\title{
STRUKTUR, KERAGAMAN DAN ASOSIASI KOMUNITAS TUMBUHAN PEMANJAT DENGAN POPULASI ALAM MERBAU DI TAMAN WISATA ALAM GUNUNG MEJA MANOKWARI-PAPUA BARAT \\ (Structure, Diversity and Association of Climbing Plants Communities with Merbau Population in Gunung Meja Natural Tourism Park of Manokwari-West Papua)
}

\author{
Elieser Viktor Sirami ${ }^{1 *}$, Djoko Marsono ${ }^{2}$, Ronggo Sadono ${ }^{2}$ dan Muhammad Ali Imron² \\ ${ }^{1}$ Program Doktor Ilmu Kehutanan, Fakultas Kehutanan Universitas Gadjah Mada \\ Jl. Agro No. 13 Bulaksumur, Yogyakarta 55281. \\ ${ }^{2}$ Fakultas Kehutanan Universitas Gadjah Mada Jl. Agro No. 13 Bulaksumur, Yogyakarta 55281.
}

*Penulis korespondensi. Tel: 081344068237. Email: siramieli@yahoo.co.id.

Diterima: 27 April 2015

Disetujui: 5 Juni 2015

\begin{abstract}
Abstrak
Struktur, keragaman dan asosiasi komunitas tumbuhan pemanjat dengan pohon inang di hutan tropis sangat ditentukan oleh banyak faktor biofisik habitat yang saling timbal balik hubungannya. Penelitian ini bertujuan untuk mengetahui struktur, keragaman dan derajat asosiasi antara tumbuhan pemanjat dengan tegakan alam merbau di TWA Gunung Meja Manokwari, Papua Barat. Hasil penelitian menunjukkan bahwa liana di bawah tegakan merbau memiliki keragaman sedang, terdiri dari 67 jenis, 52 genera dan 32 famili liana, liana berkayu 33 jenis, 29 genera dan 22 famili dan liana tak berkayu 35 jenis, 27 genera dan 19 famili. Jenis dominan adalah Pothos rumphii, dominansi sedang Philodendron sp. dan 65 jenis yang lain kurang dominan. Sebanyak 33 jenis berasosiasi sangat kuat dengan tegakan merbau, 28 jenis asosiasinya kuat dan 6 jenis asosiasinya kurang kuat. Faktor lingkungan yang berperan terhadap strukur dan keragaman serta asosiasi adalah struktur vertikal dan struktur horizontal tegakan, naungan hutan, diameter, tinggi, tekstur batang dan lebar tajuk pohon merbau dan jenis pohon yang lain.
\end{abstract}

Kata kunci: ekoregion, faktor biofisik, habitat, taman wisata, tumbuhan pemanjat, Papua.

\begin{abstract}
Reciprocal relationship among biophysical factors of habitat influence the structure, diversity and assocition levels of climbing plants with host tree in the tropical forest. The aims of this study were to know structure, diversity and assocition levels of liana and merbau population in Gunung Meja natural tourism park of Manokwari, West Papua. There were 67 species, 52 genera and 32 families of climbing plants under the merbau stands. It consists of 33 species of lianas, 29 genera, 22 families, 35 species of vines, 27 genera and 19 families and they have medium diversity levels. Pothos rumphii is the most dominant species, Philodendron sp. is medium dominant and 65 species are minimum dominant. 33 species have strong association with merbau stands, 28 species has less strong and 6 were not strong. Habitat factors that plays an important roll in the structure, diversity and assocition levels of climbing plants, were vertical and horizontal structure of forest stands, shade levels, diameters, height, crown width, texture of merbau burk and other tree species.
\end{abstract}

Keywords: biophysical factors, climbing plants, ecoregion, habitat, tourism park, Papua.

\section{PENDAHULUAN}

Taman Wisata Alam Gunung Meja Manokwari (TWA-GMM), mempunyai peran strategis bagi lingkungan hidup dan kesehatan masyarakat sebagai penyerap emisi $\mathrm{CO}_{2}$ dari kendaraan bermotor, penyuplai air bersih dan udara segar $\left(\mathrm{O}_{2}\right)$ karena terletak di tengah kota Manokwari. Fungsi Gunung Meja adalah perlindungan keanekaragaman hayati, studi ekolologi dan botani hutan, pengelolaan hutan alam, ekowisata, tata air dan perlindungan tanah. Kawasan yang status hukumnya telah diperbaharui melalui SK. Menhut Nomor. 91/Menhut-II/2012 tanggal 3 Februari 2012, dengan luas 462,16 Ha, merupakan reprensentasi atau prototipe dari kawasan hutan berbatu karang (limestone forest) di bioregion Papuasia. Gunung Meja memiliki ciri biofisik yang menarik dan mudah dijangkau, menyebabkan keberadaan Gunung Meja sangat membantu untuk kajian ekologi hutan di Papua, khususnya hutan berbatu karang.

Gunung Meja kaya akan jenis-jenis tumbuhan hutan dataran rendah dari berbagai taksa, salah satunya adalah tumbuhan pemanjat (liana dan vine) atau lebih umum disebut liana. Liana merupakan salah satu penciri hutan tropika basah dengan peran ekologis yang sangat besar namun kadang 
berdampak negatif. Diperkirakan 25\% kontribusi liana pada kepadatan dan keragaman jenis tumbuhan berkayu, struktur dan dinamika di hutan tropis (Schnitzer dkk., 2000; Schnitzer dan Bongers 2002). Liana menyumbang $2 \%$ dari biomasa per hektar di hutan tropis (Tay dkk., 2007). Di hutan tropis Asia dan Afrika, liana menyumbang kurang lebih 10-30\% biomasa di lantai hutan (Schnitzer dan Bongers 2011). Di daerah tropis yang suhunya tinggi sepanjang tahun, liana relatif lebih cepat merespon tingginya unsur $\mathrm{CO}_{2}$ dibanding pohon. Liana menjadi salah satu pengontrol respirasi yang sangat potensial sehingga walaupun kondisi panas, suhu dan kelembaban di bawah tajuk hutan tetap terjaga karena kehadiran liana. Liana menjadi penahan bagi pohon dari tiupan angin, menjadi habitat bagi burung dan sejumlah satwa liar; sebagai mikro habitat bagi beberapa jenis jamur myxomycetes di hutan tropis (Basanta dkk., 2008). Jenis-jenis liana yang saat ini sangat diperlukan dalam penataan lingkungan dalam kota sebagai tanaman hias pada ruang terbuka hijau adalah jenisjenis dengan dua kriteria utama yaitu unggul secara estetika dan kemampuan menyerap $\mathrm{CO}_{2}$. Liana merupakan sumber bahan bangunan, tali-temali, obat-obatan, makanan, bahan ritual dalam upacara adat, bahan perabotan dan perkakas yang telah lama dimanfaatkan oleh masyarakat, baik diolah secara modern maupun tradisional.

Liana pada kondisi tertentu dianggap sebagai parasit struktural bagi pohon (Stevens 1987); memperlambat laju pertumbuhan pohon (NebeNielsen 2000) meningkatkan kerusakan pohon, menyebabkan pohon tumbang dan mati (Cai 2007), memperlambat regenerasi gap hutan (Monsi dan Ogawa 1977) dan mempengaruhi fekunditas pohon (Clark dan Clark 1990). Liana menimbulkan bekas luka pada pohon yang dipanjati dan menjadi kompetitor di atas tajuk hutan dengan jenis-jenis pohon dewasa maupun permudaan pohon di bawah tajuk hutan.

Banyak manfaat ilmiah yang akan diperoleh dari pengetahuan tentang potensi ekologis liana dalam kawasan Gunung Meja, oleh karena itu data dan informasi aspek ekologi komunitas liana perlu disediakan sejak dini. Penelitian sebelumnya oleh Noya (2013), hanya menemukan 17 jenis liana yang dapat dimanfaatkan sebagai tumbuhan obat oleh masyarakat, sedangkan Sirami dkk. (2014), mencatat paling sedikit 43 jenis liana dari 30 famili yang ditemukan tumbuh bersama tegakan alam merbau. Kedua penelitian tersebut menunjukkan bahwa jumlah jenis liana yang telah diketahui hingga saat ini akan terus bertambah jika penelitian terus dilakukan. Permasalahan saat ini adalah belum banyak penelitian yang terfokus pada taksa liana karena berbagai faktor teknis maupun non teknis. Menurut Schnitzer dan Bongers (2002), walaupun liana sangat penting di hutan tropis namun pemahaman tentang liana masih sangat kurang; termasuk relatif jarang diteliti adalah liana di hutan-hutan Asia Tenggara (Cai 2007); bahkan di Indonesia pun liana kurang mendapat perhatian dalam studi-studi ekologi tumbuhan (Asrianny dkk., 2008).

Hasil penelitian liana di Gunung Meja yang minim mengindikasikan bahwa penelitian liana dari berbagai aspek masih perlu dilakukan. Oleh sebab itu salah satu aspek penting yang dituju dalam penelitian ini adalah untuk mengetahui informasi struktur, keragaman dan asosiasi jenis liana dengan populasi alam merbau di TWA Gunung Meja.

\section{METODE PENELITIAN}

\section{Lokasi Penelitian}

Penelitian dilaksanakan pada habitat tegakan alam merbau (Intsia bijuga OK.) dalam kawasan TWA-GMM dan dilanjutkan dengan identifikasi jenis liana yang belum diketahui nama botaninya di Herbarium Bogoriense, LIPI Bogor.

Luas habitat alam merbau adalah 268,4 Ha, didominasi tanah berbatu karang, tekstur liat berpasir, solum permukaan dangkal $(<50 \mathrm{~cm})$, naungan $40-98 \%$, kelerengan $2-40 \%$ (datar sampai curam), ketinggian tempat $70-174 \mathrm{~m} \mathrm{dpl}$, dengan curah hujan sangat tinggi sepanjang tahun (tipe iklim A). Vegetasi tumbuhan terdiri dari fase pohon 76 jenis dan 32 famili, tiang 91 jenis dan 38 famili, pancang 197 jenis dan 38 famili, semai 93 jenis dan 39 famili serta 42 jenis penutup tanah dari 28 famili (Sirami dkk., 2014).

\section{Pengumpulan Data}

Data yang digunakan adalah data primer dan data sekunder, teknik yang dipakai adalah sampling bertujuan atau sampel diambil karena tujuan tertentu. Bentuk plot sampel bujur sangkar ganda 5 $\mathrm{m}$ x $5 \mathrm{~m}$, teknik peletakan plot pengamatan adalah hipotetical population atau plot pengamatan diletakan sesuai dengan kondisi keberadaan tegakan alam merbau di TWA Gunung Meja.

Penelitian dimulai dengan melakukan survei lapangan dengan panduan peta sebaran alam merbau. Bila ditemukan merbau, dibuat plot pengamatan dengan ukuran $20 \mathrm{~m}$ x $20 \mathrm{~m}$ dengan menempatkan minimal satu pohon merbau sebagai titik pusat plot. Di dalam plot $20 \mathrm{~m}$ x $20 \mathrm{~m}$, dibuat lagi plot berukuran $5 \mathrm{~m}$ x $5 \mathrm{~m}$ untuk mengamatan dan pendataan liana. Variabel yang diamati adalah nama jenis, famili, jumlah individu tiap jenis dan sifat batang liana. 


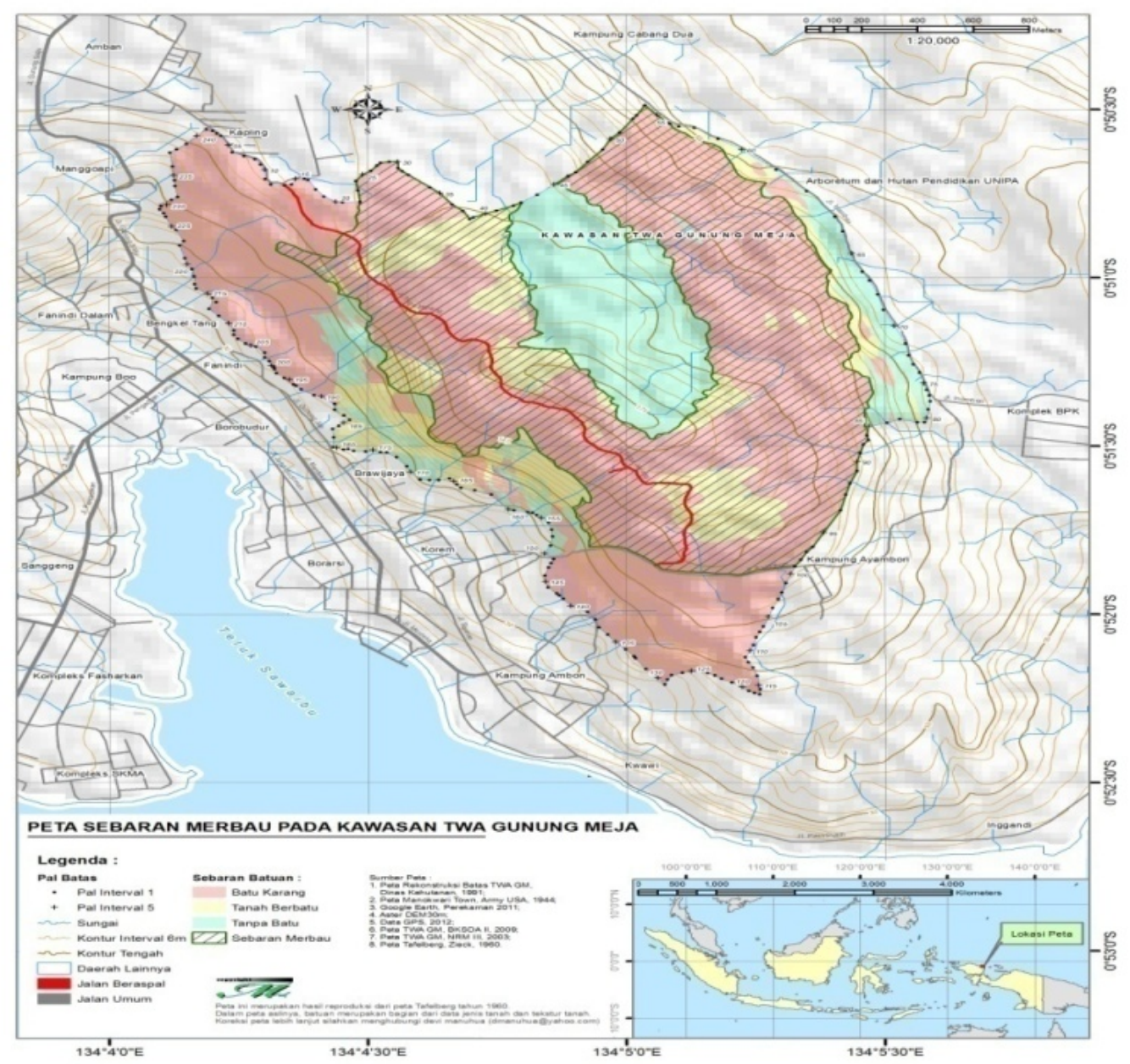

Gambar 1. Peta area sebaran alam pohon merbau (Intsia bijuga OK.) di TWA Gunung Meja Manokwari (Sumber: Sirami dkk., 2014).

\section{Analisis Data}

\section{Struktur, komposisi dan derajat asosiasi liana dengan merbau}

Struktur dan komposisi jenis liana didekati dengan persamaan analisis vegetasi dan derajat asosiasi diidentifikasi menggunakan Indeks Dice (DI) ( Ludwig dan Reynold 1988).

$\operatorname{Kerapatan}(K)=\frac{\sum \text { Individu liana jenis } k e-i}{\text { Luas unit sampling }(U S)}$

Kerapatan Relatif $(K R)=\frac{K \text { Liana jenis ke- } i}{K \text { Seluruh jenis }} \times 100 \%$

Frekuensi $(F)=\frac{\sum U S \text { ditemukan jenis liana ke-i }}{\sum T \text { Total } U S}$

Frekuensi Relatif $(F R)=\frac{\sum_{F \text { Jenis liana ke }-i}}{F \text { Seluruh Jenis }} \times 100 \%$

Indeks Nilai Penting $(I N P)=K R+F R$

Dibuat juga kelas dominansi liana (tinggi, sedang, rendah) berdasarkan indeks nilai penting (INP) untuk menentukan urutan dominansi jenis (Mueller-Dombois dan Ellenberg 1974).

\section{Indeks Dice (DI)}

Menyusun data binari, bila ada (presence) jenis merbau dan jenis liana ke-i pada unit sampling ke- $n$ ditulis 1 dan bila tidak ada (absence) ditulis 0 .
Di dalam semua plot sudah pasti terdapat merbau, maka asosiasi ini disebut complete association (Ludwig dan Reynold 1988), oleh sebab itu persamaan indeks Dice (DI) disesuaikan sebagai berikut:

$\mathrm{a}=$ Frekuensi ditemukannya merbau dengan jenis liana ke-i

b = Frekuensi ditemukannya merbau dengan bukan jenis liana ke-i

Indeks Dice $(D I)=\frac{2 a}{2 a+b}$

Bila nilai $\mathrm{DI}=0$, tidak ada asosiasi dan nilai DI $=1$, asosiasi maksimal. Agar dapat dibedakan derajat asosiasi antara merbau dengan jenis liana ke-i, maka dibuat kelas asosiasi (rendah, sedang dan tinggi) berdasarkan nilai indeks Dice (DI).

\section{Keragaman jenis liana}

Keragaman (H) dan kemerataan (E) jenis, menggunakan indeks Shannon-Wiener (H) (Pretzsch 2009).

Keragaman Jenis $\left(H^{\prime}\right)=-\sum_{n=1}^{S}\left(\frac{n_{i}}{N} \times \ln \frac{n_{i}}{N}\right)$

Keragaman Maksimum $\left(H^{\max }\right)=\ln S$

Kemerataan Jenis $(E)=\left(\frac{H}{H^{\max }}\right) \times 100 \%$ 
Keterangan

$\mathrm{N}=$ Total jumlah individu seluruh jenis

$\mathrm{ni}=$ Jumlah individu jenis ke-i

$\mathrm{S}=$ Total jenis

\section{HASIL DAN PEMBAHASAN}

\section{Struktur Komunitas Liana}

Jumlah plot yang dilakukan pengamatan adalah 156, jumlah pohon merbau 345 individu, dalam satu plot terdapat 1-5 pohon atau rata-rata 2,22 pohon per plot. Sebaran diameter merbau 20 $\mathrm{cm}-120 \mathrm{~cm}$, tinggi total 4-31 m, lebar tajuk 7-26 $\mathrm{m}$, kepadatan rata-rata liana per plot 15 individu, dengan 7-10 jenis per plot.

Kelimpahan jenis liana di bawah tegakan merbau adalah 2.289 individu dengan kepadatan 5.689 individu/Ha. Liana berkayu (liana) 442 individu, kepadatan 1.082 individu/Ha, liana tak berkayu (vine) kelimpahannya 1.867 individu, kepadatan 4.757 individu/Ha. Jenis dengan dominansi tertinggi adalah Pothos rumphii (INP 42,14), dominansi sedang Philodendron sp. (INP 20,71), dan 65 jenis yang lain tergolong jenis kurang dominan (INP 13,98-0,31).

Jenis-jenis liana dominan merupakan jenis yang mampu beradaptasi terhadap kondisi fisik habitat di bawah tegakan merbau. Sepuluh jenis dengan INP tertinggi (Tabel 1) didominasi jenisjenis liana tidak berkayu. Jenis-jenis liana dengan sifat batang lunak sangat memerlukan air dalam jumlah yang optimal, dan bila jenis-jenis itu dominan ini artinya suplai air di bawah tegakan merbau sangat mencukupi. Faktor lain adalah cepat tumbuh dan kemampuan menyimpan air dan menyuplai air sangat baik, sehingga bila terjadi peningkatan temperatur di bawah tegakan dan menyebabkan penguapan yang tinggi, masih terdapat cadangan air yang bisa digunakan untuk proses-proses metabolisme. Jenis liana tak berkayu lebih efisien memanfaatkan ruang pada batang pohon inang maupun di bawah tegakan hutan, karena didukung secara mekanis dengan adventitious roots dan tendril. Faktor berikutnya adalah mekanisme penyebarannya sangat mendukung sehingga area pemencarannya lebih luas. Jenis-jenis seperti yang dimaksud biasanya mode pemencarannya dengan bantuan hewan (zookori) dan angin (anemokori). Faktor yang lain adalah jumlah permudaan yang dihasilkan sangat banyak, misalnya tali kuning atau akar kuning (Arcangesia flava (L) Mer.).

\section{Keragaman Jenis Liana}

Indeks keragaman $\left(\mathrm{H}^{\prime}\right)=3,00, \ln \mathrm{S}=4,20$ dan kemerataan jenis $(E)=71,30$, menunjukkan tingkat keragaman dan kemerataan jenis liana tergolong sedang. Secara ekologis nilai keragaman dan kemerataan jenis menandakan bahwa komunitas liana tergolong besar dan beraneka ragam karena disusun oleh banyak jenis dengan kelimpahan sedang dan sedikit jenis dengan kelimpahan kecil dan besar. Menurut Ludwig dan Reynolds (1988), suatu komunitas dikatakan mempunyai keragaman tinggi jika terdiri dari banyak jenis dengan kelimpahan sama atau hampir sama.

Keragaman liana dibentuk oleh 67 jenis, 52 genera dan 32 famili liana ditemukan di bawah tegakan merbau (Tabel 1). Liana berkayu (liana) terdiri dari 33 jenis, 29 genera dan 22 famili dan liana tak berkayu (vine) 35 jenis, 27 genera dan 19 famili. Genera dengan sumbangsih terbesar bagi keragaman jenis adalah Piper 6 jenis (12\%), Smilax 4 jenis (8\%), disusul Calamus, Derris, Ficus, Frycenetia, Gnetum, Pothos dan Psychotria masing-masing 2 jenis (3\%). Famili dengan sumbangan keragaman paling besar adalah Piperaceae menyumbang 6 jenis (18\%), Rubiaceae dan jenis (17\%), Smilacaceae, Fabaceae dan Menispermaceae 4 jenis (13\%), Annonaceae, Moraceae dan Euphorbiaceae masing-masing 3 jenis (9\%), sedangkan 24 famili lainnya ada yang menyumbang 2 (6\%) dan 1 jenis (3\%).

Genera liana berkayu dengan sumbangan keragaman terbesar adalah Erycibe, Derris dan Gnetum masing menyumbang 2 jenis (7\%) sedangkan 26 genera yang lain hanya menyumbang satu jenis (3\%). Famili dengan sumbangan jenis terbanyak adalah Rubiaceae 4 jenis (13\%), diikuti Fabaceae 4 jenis (9\%), Annonaceae, Compositae, Euphorbiaceae, Moraceae masing-masing 2 jenis (6\%), dan 15 famili yang lain menyumbang satu jenis (3\%). Secara keseluruhan golongan liana berkayu menyumbang $48 \%$ jenis, $56 \%$ genera dan $67 \%$ famili bagi keragaman jenis liana yang tumbuh di bawah tegakan merbau.

Penyumbang keragaman terbesar liana tak berkayu adalah genera Piper dengan 6 jenis (22\%), Smilax 4 jenis (15\%), diukuti Pothos, Calamus dan Fraycenetia masing-masing 2 jenis (7\%) dan sisa genera yang lain menyumbang 1 jenis (4\%). Famili dengan jenis terbanyak adalah Piperaceae 6 (32\%), diikuti Araceae dan Smilacaceae masing-masing 4 jenis (21\%), Menispermaceae 3 jenis (16\%), Arecaceae, Asclepidaceae, Pandanaceae dan Vitaceae masing-masing 2 jenis (11\%), 9 famili yang lain menyumbang 1 jenis (5\%). Liana tak berkayu mempunyai sumbangsih $52 \%$ jenis dan $52 \%$ genera serta $56 \%$ famili bagi keragaman jenis liana yang tumbuh di bawah tegakan alam merbau. Untuk famili yang anggota jenisnya termasuk kelompok liana berkayu dan tidak berkayu adalah Annonaceae, Convolvulaceae, Euphorbiaceae, 
Tabel 1. Struktur komunitas tumbuhan pemanjat (liana dan vine) pada tegakan alam merbau di TWA Gunung Meja Manokwari.

\begin{tabular}{|c|c|c|c|c|}
\hline No. & Nama jenis & Famili & Sifat batang & INP \\
\hline 1. & Pothos rumphii & Araceae & Tidak berkayu & 42,14 \\
\hline 2. & Philodendron sp. & Araceae & Tidak berkayu & 20,71 \\
\hline 3. & Piper canimum & Piperaceae & Tidak berkayu & 13,98 \\
\hline 4. & Arcangesia flava & Menispemaceae & Tidak berkayu & 12,71 \\
\hline 5. & Piper sp1. & Piperaceae & Tidak berkayu & 10,21 \\
\hline 6. & Salacia chinensis L. & Celastraceae & Berkayu & 9,21 \\
\hline 7. & Pycnarrhena grandis K. Schum. \& Lauterb. & Menispermaceae & Berkayu & 6,74 \\
\hline 8. & Pothos scandens & Araceae & Tidak berkayu & 6,74 \\
\hline 9. & Friesodielsia cf. cuneiformis (Blume) Steenis. & Annonaceae & Berkayu & 6,58 \\
\hline 10. & Smilax malabaricum & Smilacaceae & Tidak berkayu & 5,49 \\
\hline 11. & Bauhinia tomentosa & Fabaceae & Berkayu & 5,40 \\
\hline 12. & Psychotria sarmentosa Blume. & Rubiaceae & Berkayu & 4,29 \\
\hline 13. & Derris elegans Benth. & Fabaceae & Berkayu & 3,43 \\
\hline 14. & Calamus cayensis & Arecaceae & Tidak berkayu & 3,11 \\
\hline 15. & Gnetum latifolium Blume var. latifolium & Gnetinaceae & Berkayu & 2,73 \\
\hline 16. & Smilax cf Smilax trifoliata & Smilacaceae & Tidak berkayu & 2,38 \\
\hline 17. & Derris aff. trifoliata spiny & Fabaceae & Berkayu & 2,23 \\
\hline 18. & Geitonoplesium cymosum (R.Br.) R. Br. & Philesiaceae & Berkayu & 2,19 \\
\hline 19. & Allophyllus cobbe (L.) Reausch. & Sapindaceae & Berkayu & 1,64 \\
\hline 20. & Adenia heterophylla (Blume) Koord. & Passifloraceae & Berkayu & 1,60 \\
\hline 21. & Hoya sp. & Euphorbiacaea & Tidak berkayu & 1,40 \\
\hline 22. & Uvaria purpurea Blume. & Annonaceae & Tidak berkayu & 1,40 \\
\hline 23. & Frycenetya scandens & Pandanaceae & Tidak berkayu & 1,36 \\
\hline 24. & Rhaphidophora sp. & Araceae & Tidak berkayu & 1,36 \\
\hline 25. & Tetrastigma sp. & Vitaceae & Tidak berkayu & 1,29 \\
\hline 26. & Vernonia sp. & Compositae & Berkayu & 1,22 \\
\hline 27. & Artabotrys suaveolens Blume. & Annonaceae & Berkayu & 1,14 \\
\hline 28. & Piper betle & Piperaceae & Tidak berkayu & 1,14 \\
\hline 29. & Piper sp2. & Piperaceae & Tidak berkayu & 1,14 \\
\hline 30. & Frycenetya sp. & Pandanaceae & Tidak berkayu & 1,07 \\
\hline 31. & Luvunga eleutherandra Dalzell. & Rutaceae & Berkayu & 1,05 \\
\hline 32. & Piper sp3. & Piperaceae & Tidak berkayu & 1,03 \\
\hline 33. & Ficus subulata & Moraceae & Berkayu & 1,01 \\
\hline 34. & Blumea chinensis (L) DC. & Compositae & Berkayu & 0,96 \\
\hline 35. & Urceola javanica (Blume) Boerl. & Apocynaceae & Tidak berkayu & 0,96 \\
\hline 36. & Flagellaria indica & Flagellariaceae & Tidak berkayu & 0,94 \\
\hline 37. & Enkleia sp. & Thymelaeaceae & Berkayu & 0,92 \\
\hline 38. & Nothocissus penninervis (F. Muell.) Latiff. & Vitaceae & Tidak berkayu & 0,81 \\
\hline 39. & Tecomaria sp. & Bignoniaceae & Berkayu & 0,81 \\
\hline 40. & Cudrania sp. & Moraceae & Berkayu & 0,77 \\
\hline 41. & Lophopyxis maingayi Hook. F. & Euphorbiacaea & Berkayu & 0,77 \\
\hline 42. & Matelea sp. & Asclepiadaceae & Tidak berkayu & 0,77 \\
\hline 43. & Smilax china & Smilacaceae & Tidak berkayu & 0,74 \\
\hline 44. & Cucurbita sp. & Cucurbitaceae & Tidak berkayu & 0,72 \\
\hline 45. & Lepionurus sylvestris Blume. & Opiliaceae & Berkayu & 0,70 \\
\hline 46. & Caparis sepiaria L. & Capparaceae & Berkayu & 0,66 \\
\hline 47. & Gnetum genemonoides & Gnetinaceae & Berkayu & 0,66 \\
\hline 48. & Randia uncaria Elmer. & Rubiaceae & Berkayu & 0,66 \\
\hline 49. & Psychotria sp. & Rubiaceae & Berkayu & 0,63 \\
\hline 50. & Smythea lanceata (Tul) Summerh. & Rhamnaceae & Berkayu & 0,63 \\
\hline 51. & Ficus sagitata & Moraceae & Tidak berkayu & 0,61 \\
\hline 52. & Smilax vitiensis A. DC. & Smilacaceae & Tidak berkayu & 0,59 \\
\hline 53. & Cipholophus sp. & Urticaceae & Berkayu & 0,55 \\
\hline 54. & Erycibe malaccensis C. B. Clarke. & Convolvulaceae & Berkayu & 0,55 \\
\hline 55. & Iodes philippinensis Merr. & Icacinaceae & Berkayu & 0,55 \\
\hline 56. & Piper umbellatum & Piperaceae & Tidak berkayu & 0,55 \\
\hline 57. & Mucuna novaguinensis & Fabaceae & Berkayu & 0,50 \\
\hline 58. & Anamirtha cocculus & Menispemaceae & Tidak Berkayu & 0,46 \\
\hline 59. & Cardiospermum sp. & Ranunculaceae & Berkayu & 0,46 \\
\hline 60. & Cynanchum ovalifolium Wigth. & Asclepiadaceae & Tidak berkayu & 0,46 \\
\hline 61. & Merremia umbelifera & Convolvulaceae & Tidak berkayu & 0,46 \\
\hline 62. & Zononia sp. & Rubiaceae & Tidak berkayu & 0,39 \\
\hline 63. & Menisperma sp. & Menispemaceae & Tidak berkayu & 0,35 \\
\hline 64. & Mussaenda frandosa & Rubiaceae & Berkayu & 0,35 \\
\hline 65. & Paederia foetida & Rubiaceae & Tidak berkayu & 0,35 \\
\hline 66. & Calamus aruensis & Arecaceae & Tidak berkayu & 0,31 \\
\hline 67. & Croton caudatus Geiseler. & Euphorbiacaea & Berkayu & 0,31 \\
\hline
\end{tabular}

Sumber: Data primer, diolah (2015) 
Fabaceae, Menispermaceae, Rubiaceae dan Moraceae.

Sebagai pembanding antara hutan Gunung Meja mewakili bioregion Papuasia dengan hutan tropis wilayah Asia, Lu dkk. (2009), mencatat ratarata 440 batang liana dengan diameter $1-10 \mathrm{~cm}$ dbh/Ha ditemukan di Sarawak. Putz dan Chai (1987), menemukan rata-rata 348 batang/Ha di Sarawak lembah dan $164(>2 \mathrm{~cm}$ dbh) di situs puncak bukit. 23 jenis, 142 individu, 12 famili dan 16 genera ditemukan dalam luasan 8 Ha di kawasan konservasi lembah Imbak Sabah Malaysia (Kammesheidt dkk., 2009). Perbandingan ini tidak mutlak digunakan sebagai acuan tingkat kekayaan jenis, karena perbedaan metode terutama kriteria diameter batang yang didata. Informasi tersebut sedapat mungkin memberikan gambaran awal mengenai kekayaan minimum jenis liana per hektar pada wilayah-wilayah yang perdibandingkan.

Fenomena kelimpahan, struktur dan keragaman jenis liana di hutan Gunung Meja memang belum dapat dijelaskan secara tegas karena frekuensi penelitian ekologi yang dilakukan juga sangat minim bahkan belum ada. Struktur dan kelimpahan jenis liana yang kami dapati dalam penelitian ini ditentukan oleh iklim makro dan mikro di lokasi penelitian serta struktur vegetasi yang sangat beragam. Iklim mikro yang terjadi sangat ditentukan oleh rapatnya vegetasi dan tutupan tajuk hutan. Merbau memainkan peranan penting dalam dinamika komunitas liana melalui posisinya pada strata paling atas yaitu strata A dan B sehingga memberikan naungan yang cukup bagi liana. Selain itu ukuran diameter dan tingginya memudahkan liana menjadikannya sebagai pohon inang. Faktor tanah kurang berperan terhadap pertumbuhan dan perkembangan serta kehadiran jenis-jenis liana, karena habitat liana didominasi oleh tanah berkarang yang miskin hara.

Faktor-faktor yang mengontrol struktur dan keragaman jenis liana yang ditemukan di hutan Gunung Meja menunjukkan pola-pola yang sangat umum dan sering ditemukan pada beberapa areal hutan di wilayah tropis Asia, Afrika atau Amerika. Walaupun sebenarnya di Gunung Meja hanya beberapa faktor saja yang pengaruhnya cukup jelas teramati selama berlangsungnya penelitian.

Dari sejumlah penelitian yang telah dilakukan sebelumnya, diketahui ada beberapa faktor biofisik habitat yang berperan penting dalam pembentukkan struktur dan tingkat keragaman jenis liana. Faktor pertama adalah tipe hutan, menurut Cai dkk. (2009), tipe hutan merupakan variabel yang menentukan penyebaran liana berdasarkan cara memanjat dan kepadatan. Pada hutan berdaun lebar dan hijau sepanjang tahun, jumlah liana per hektar lebih tinggi dibanding hutan bergunung dan hutan berdaun jarum. Pada hutan daun lebar dan bergunung jenis liana paling banyak menyebar karena faktor hewan dan gravitasi. DeWalt dkk. (2006), melaporkan bahwa hutan karangas di Kalimantan memiliki liana yang tumbuh dalam struktur komunitas yang lebih kompleks dan keragaman yang tinggi dibanding hutan dengan tanah aluvial dan berpasir.

Faktor kedua berupa tanah, yang meliputi tekstur dan unsur hara tanah. Tanah yang kaya akan nutrisi sangat berpengaruh pada kepadatan dan keragaman jenis liana. Di hutan dataran rendah Negeri Sembilan, kehadiran beberapa jenis liana ditentukan oleh $\mathrm{pH}$ tanah, bahan organik total, bahan organik tersedia seperti Mg, K dan P. Famili dengan jenis paling banyak yang ditemukan adalah annonaceae dengan 33 jenis (Nurfazliza dkk., 2012).

Faktor ketiga adalah topografi habitat, yang meliputi ketinggian tempat dan kelerengan. Kepadatan liana dalam gap hutan yang kecil ditentukan juga oleh karakteristik lanskap seperti topografi karena mengendalikan iklim mikro melalui posisi gap terhadap arah datangnya cahaya. Biasanya dalam kondisi seperti ini, jenis liana yang memiliki sulur menjadi lebih dominan kerena tidak membutuhkan ruang yang besar untuk tumbuh, namun kurang dominan bila dibanding jenis liana yang memiliki duri pemanjat dalam hal mendapat tempat paling tinggi pada pohon inang (Malizia dan Grau 2008). Jika ditinjau dari sisi elevasi habitat, maka faktor ketinggian tidak mengontrol rata-rata kepadatan dan basal area liana, namun rata-rata diameter liana secara signifikan menurun mengikuti ketinggian tempat (Homeier dkk., 2010). Diperjelas lagi oleh Alves dkk. (2012), bahwa variasi pada gap hutan yang terbentuk dan temperatur rendah mengikuti ketinggian tempat berpengaruh pada kepadatan liana, namun tidak pada biomasanya kerena liana memiliki ukuran batang yang relatif besar.

Faktor keempat berupa iklim, yang meliputi cahaya dan temperatur udara serta curah hujan. Iklim yang sejuk di bawah tegakan hutan, curah hujan tahunan dan bulanan yang mencukupi suplai air dan intensitas cahaya yang tinggi tidak saja mempengaruhi kepadatan dan keragaman melainkan juga pola-pola spasial liana di hutan tropis (Nogueira dkk., 2011). Pengaruh cahaya dijelaskan pula secara berbeda oleh Carrasco-Urra dan Gianoli (2009), bahwa ketersediaan cahaya dalam hutan tidak mempengaruhi kelimpahan liana tak berkayu ketika jumlah dan ukuran pohon inang diperhitungkan; karena liana menggunakan pohon inang untuk mencapai tempat tertinggi yang 
menyediakan cahaya, artinya liana tidak menunggu cahaya optimal mencapai lantai hutan, melainkan berkompetisi untuk mendapatkan cahaya di atas tajuk hutan.

Faktor kelima yakni struktur vegetasi, yang meliputi kerapatan vegetasi dan ciri fisik pohon atau pohon inang. Struktur vegetasi sangat penting artinya karena mengontrol faktor iklim mikro dan dalam waktu yang lama, berandil besar atas perubahan kandungan nutrisi tanah hutan bagi liana. Gap hutan yang terbentuk merupakan gambaran dari terganggunya struktur hutan, dan menjadi tempat favorit bagi sebagian besar liana tak berkayu.

Menurut Nogueira dkk. (2011), pola spasial komunitas liana di hutan tropis berhubungan erat dengan struktur vegetasi. Malizia dkk. (2010), menjelaskan bahwa di hutan tropis yang sudah berkembang lebih lanjut struktur dan kepadatan liana berhubungan dengan peningkatan formasi gap hutan. Diperjelas oleh Anbarashan dan Parthasarathy (2013), bahwa kepadatan liana pada berbagai rejim kerusakan hutan menunjukkan kecenderungan meningkat sejalan dengan meningkatnya tingkat kerusakan, namun sebaliknya menunjukkan penurunan basal area. Jenis-jenis dengan mekanisme penjalaran menggunakan batang pelilit (twiner) sangat dominan dengan mode penyebaran anemokori. Ledo dan Schnitzer (2014) menambahkan bahwa liana akan merespon pembentukan gap melalui reproduksi vegetatif atau mengeluarkan tunas baru maupun cabang pada batang dan membentuk pola distribusi spasial secara mengelompok. Laurance dkk. (2014) mengatakan bahwa setelah dilakukan penyelidikan selama lebih dari lima tahun di hutan primer tua Amazon, disimpulkan bahwa kepadatan liana akan meningkat sebagai reaksi atas dinamika hutan dan peningkatan $\mathrm{CO}_{2}$. Fakta tersebut menunjukkan kemampuan mereduksi $\mathrm{CO}_{2}$ oleh liana sangat baik. Pada gap hutan, liana menyebabkan persaingan yang ketat terhadap penyerapan karbon oleh pohon. Penelitian yang dilakukan di Panama selama 8 tahun menunjukkan bahwa rata-rata $280 \%$ terjadi akumulasi karbon lebih tinggi pada pohon yang tidak ditemukan liana dibanding yang pohon yang terdapat liana (Schnitzer dkk., 2014). Ada korelasi antara pengurangan tingkat pertumbuhan biomasa pohon inang sebesar $10 \%$ karena liana, namun terjadi juga peningkatan biomasa total hutan sebesar 30\% (Van der Heijden dan Phillips 2009).

Malizia dkk. (2010), menjelaskan pula bahwa karakter pohon inang mempunyai peran yang cukup penting pada kepadatan liana; jumlah liana per pohon inang meningkat mengikuti besarnya ukuran diameter pohon (Homeier dkk., 2010). Secara keseluruhan, kelimpahan liana meningkat dengan peningkatan diameter batang pohon inang, sedangkan jenis pohon inang tidak memberikan perbedaan. Kelimpahan relatif liana berbatang pelilit (twiner) dan akar penempel menurun dan meningkat mengikuti ukuran dimeter pohon inang (Carrasco-Urra dan Gianoli 2009).

\section{Asosiasi Komunitas Liana dengan Merbau}

Hasil perhitungan indeks asosiasi Dice (DI) menunjukkan bahwa 33 jenis liana atau 49\% dari total jenis, terdiri dari 17 jenis liana berkayu dan 16 jenis tidak berkayu ditemukan lebih sering tumbuh di bawah tegakan merbau dengan nilai DI 0,920,074. Diketahui juga 28 jenis (42\%) terdiri dari 13 jenis liana berkayu dan 15 jenis tidak berkayu ditemukan dengan frekuensi sedang (DI 0,0620,038) dan 6 jenis (9\%), 2 jenis liana berkayu dan 4 jenis bukan liana berkayu kehadirannya sangat jarang (DI 0,025). Umumnya, dua faktor utama yang menentukan terjadinya asosiasi merbau dengan jenis liana di TWA-GMM adalah iklim mikro yang stabil di bawah tegakan merbau, dan titian oleh pohon-pohon merbau bagi liana untuk mencapai tajuk hutan tertinggi karena merbau merupakan jenis dominan pada strata A dan B.

Secara ekologi, asosiasi antara dua individu tumbuhan sejenis atau bukan sejenis berawal dari tumbuh bersama dalam relung ekologi yang sama (Mueller-Dombois dan Ellenberg 1974; Barbour dkk., 1987), ini artinya asosiasi tidak mutlak dipengaruhi oleh kepadatan tiap jenis melainkan banyak faktor lain mungkin acak pengaruhnya. Oleh sebab itu jenis-jenis liana yang memiliki asosiasi tinggi dengan pohon merbau belum tentu jenis dominan kerena kepadatan populasi suatu jenis hanya sebagian kecil faktor penentu asosiasi. Asosiasi dapat terjadi karena kesesuaian fisiologis maupun morfologi liana dan pohon inang merbau maupun pohon lain. Namun dapat juga terjadi karena faktor fisik habitat seperti kebutuhan akan nuangan, iklim mikro seperti cahaya dan temperatur. Menurut Padaki dan Parthasarathy (2000), jenis yang sangat dominan memanfaatkan pohon-pohon besar sebagai inang adalah jenis liana yang menggunakan batang pelilit (twiner) dan akar penempel, serta liana memilih jenis pohon inang secara acak. Liana memiliki hubungan langsung dengan pohon-pohon karena liana tersebut menggunakan pohon sebagai pendukung langsung bagi pertumbuhan (Addo-Fordjour dkk., 2009; Reddy dan Parthasarathy 2006), dan merupakan penentu utama keanekaragaman dan kelimpahan jenis liana tersebut (Laurance dkk., 2001; AddoFordjour dkk., 2008). 
Pohon inang sangat besar artinya bagi pertumbuhan liana terutama jenis-jenis liana tak berkayu. Berbeda dengan jenis liana berkayu yang tidak sepanjang fase hidupnya memerlukan inang, karena ketika fase permudaan masih berupa semak. Fungsi pohon inang bagi liana adalah sebagai sandaran, naungan sekaligus sebagai titian untuk mencapai tajuk hutan tertinggi yang menyediakan cahaya optimal. Seperti di hutan kering Bolivia, tingkat asosiasi antar liana dan pohon inang dipengaruhi ciri-ciri morfologi dan fisiologis yang dianggap memfasilitasi atau menghambat liana membentuk koloni pada pohon sebagai inang. Penyebaran cabang, laju pengelupasan kulit, tekstur kulit, fleksibilitas batang, dan tinggi batang bebas cabang merupakan faktor-faktor yang membedakan kolonisasi di antara spesies liana pada pohon inang (Carse dkk., 2000). Di hutan konservasi Bobiri Ghana, lebih banyak jenis dan jumlah liana ditemukan pada pohon-pohon besar dibanding pohon-pohon kecil sebagai efek dari sistem pengelolaan yang diterapkan (Addo-Fordjour dkk., 2009).

Selama penelitian dilaksanakan, didapati bahwa asosiasi yang terjadi antara komunitas liana dan merbau dipengaruhi secara langsung oleh faktor naungan hutan, tinggi, tekstur kulit, lebar tajuk dan diameter pohon. Terdapat pula beberapa faktor lain tetapi pengaruhnya tidak teramati secara langsung seperti cahaya, kelembaban dan temperatur.

\section{KESIMPULAN}

Struktur dan komposisi jenis liana, tingkat keragaman dan derajat asosiasi liana dengan merbau di TWA Gunung Meja Menokwari, tidak dipengaruhi secara langsung oleh faktor tanah dan cahaya, melainkan kerena faktor struktur vertikal tegakan (strata hutan) dan struktur horizontal tegakan (keragaman, kerapatan sebaran pohon), naungan hutan, tinggi, diameter, tekstur batang, lebar tajuk pohon merbau dan karakteristik jenis pohon lain yang tumbuh di sekitar pohon merbau.

\section{DAFTAR PUSTAKA}

Addo-Fordjour, P., Anning, A.K., Atakora, E.A., dan Agyei, P.S., 2008. Diversity and Distribution of Climbing Plants in a SemiDeciduous Rain Forest, KNUST Botanic Garden, Ghana. International Journal of Botany, 4:186-195.

Addo-Fordjour, P., Anning, A.K., Larbi, J.A., dan Akyeampong, S., 2009. Liana Species Richness, Abundance and Relationship with
Trees in The Bobiri Forest Reserve, Ghana: Impact of Management Systems. Forest Ecology and Management, 257(8):1822-1828.

Alves, L.F., Assis, M.A., Van Melis, J., Barros, A.L.S., Vieira, S.A., Martins, F.R., Martinelli, L.A., dan Joly, C.A., 2012. Variation in Liana Abundance and Biomass Along An Elevational Gradient in The Tropical Atlantic Forest (Brazil). Ecological Research, 27(2):323-332.

Anbarashan, M., dan Parthasarathy, N., 2013. Diversity and Ecology of Lianas in Tropical Dry Evergreen Forests on The Coromandel Coast of India Under Various Disturbance Regimes. Flora, 208:22-32.

Asrianny, Marian, dan Oka, N.P., 2008. Keanekaragaman dan Kelimpahan Jenis Liana (Tumbuhan Memanjat) pada Hutan Alam di Hutan Pendidikan Universitas Hassanudin. Jurnal Parenial, 5(1):23-30.

Barbour, M.G., Burk, J.H., dan Pitts, W.D., 1987. Terrestrial Plant Ecology. $2^{\text {nd }}$ Ed. The Benjamin/Cumming Publishing Company, Inc., New York. Pp 105-119.

Cai, Z-Q, Schnitzer, S.A., Wen, B., Chen, Y.J., dan Bongers, F., 2009. Liana Communities in Three Tropical Forest Types in Xishuangbanna, South-West China. Journal of Tropical Forest Science, 21(3):252-264.

Cai, Z.Q., 2007. Lianas and Trees in Tropical Forests in South China. PhD Thesis. Department of Environmental Sciences, Wageningen University, Wageningen.

Carrasco-Urra, F., dan Gianoli, E., 2009. Abundance of Climbing Plants in a Southern Temperate Rain Forest: Host Tree Characteristics or Light Availability? Journal of Vegetation Science, 20(6):1155-1162.

Carse, L.E, Fredericksen, T.S., dan Licona, J.C., 2000. Liana -Tree Species Associations in A Bolivian Dry Forest. Tropical Ecology, 41(1):1-10.

Clark, D.B., dan Clark, D.A., 1990. Distribution and Effects on Tree Growth of Lianas and Woody Hemiepiphytes in A Costa Rican Tropical Wet Forest. Journal of Tropical Ecology, 6:321-331.

De Basanta, W.D., Stephenson, S.L., Lado, C., Estrada-Torres, A., dan Nieves-Rivera, A.M., 2008. Lianas as a Microhabitat for Myxomycetes in Tropical Forests. Fungal Diversity, 28:109-125.

DeWalt, S.J., Ickes K., Nilus, R., Harms, K.E., dan Burslem, D.F.R.P., 2006. Liana Habitat Associations and Community Structure in A 
Bornean Lowland Tropical Forest. Plant Ecology, 186:203-216.

Homeier, J., Englert, F., Leuschner, C., Weigelt, P., dan Unger, M., 2010. Factors Controlling The Abundance of Lianas Along An Altitudinal Transect of Tropical Forests in Ecuador. Forest Ecology and Management, 259:13991405.

Kammesheidt, L., Berhaman, A., Tay J., Abdullah, G., dan Azwal, M., 2009. Liana Abundance, Diversity and Tree Infestation in The Imbak Canyon Conservation Area, Sabah, Malaysia. Journal of Tropical Forest Science, 21(3):265271.

Laurance, W.F., Andrade, A.S., Magrach, A., Jose, L.C., Valsko, J.J., Campbell, M., Fearnside, P.M., Edwards, W., Lovejoy, T.E., dan Laurance, S.G., 2014. Long-Term Changes in Liana Abundance and Forest Dynamics in Undisturbed Amazonian Forests. Ecology, 9 (6):1604-1611.

Laurance, W.F., Pe'rez-Salicrup, D., Delamonica, P., Fernside, P.M., D’Angelo, S., Jerozolinski, A., Pohl, L., dan Lovejoy, T.E., 2001. Rainforest Fragmentation and The Structure of Amazonian Liana Communities. Ecology, 82(1):105-116.

Ledo, A., dan Schnitzer, S.A., 2014. Disturbance and Clonal Reproduction Determine Liana Distribution and Maintain Liana Diversity in A Tropical Forest. Ecology, 95(8):2169-2178.

Londre, R.A., dan Schnitzer, S.A., 2006. The Distribution of Liana and Their Change in Abudance in Temperate Forest Over 45 Years. Ecology, 8(12):2973-2978.

Lu, X.T., Tang, J.W., Feng, Z.L., dan Li, M.H., 2009. Diversity and Aboveground Biomass of Lianas in The Tropical Seasonal Rain Forests of Xishuangbanna, SW China. International Journal of Tropical Biology, 57(1-2):211-222.

Ludwig, J.A., dan Reynolds, J.F., 1988. Statistical Ecology: A Primer on Method and Computing. John Wiley \& Sons, Inc., New York, pp 125144.

Malizia, A., dan Grau, H.R., 2008. Landscape Context and Microenvironment Influences on Liana Communities within Treefall Gaps. Journal of Vegetation Science, 19(5):597-604.

Malizia, A., Grau, H.R., dan Lichstein, J.W., 2010. Soil Phosphorus and Disturbance Influence Liana Communities in A Subtropical Montane Forest. Journal of Vegetation Science, 21(3):551-560.

Monsi, M., dan Ogawa, K., 1977. Ecological Considerations on Some Characteristics of Liana Communities, dalam Proceeding of
International Symposium on Protection of Environment. Maruzen, Tokyo, pp 325-336.

Mueller-Dombois, D., dan Ellenberg, H., 1974. Aims and Methods of Vegetation Ecology. John Wiley \& Sons, New York. Pp 359-367.

Nabe-Nielsen, J., 2000. Liana Community and Population Ecology in a Neotropical Rain Forest. Ph.D. Dissertation, Faculty of Natural Sciences, Aarhus University, Aarhus.

Nogueira, A., Costa, F.R.C., dan Castilho, C.V., 2011. Liana Abundance Patterns: The Role of Ecological Filters During Development. Biotropica, 43(4):442-449.

Noya, J., 2013. Tumbuhan Obat di Hutan Taman Wisata Alam Gunung Meja Kabupaten Manokwari Provinsi Papua Barat. Skripsi Jurusan Kehutanan, Fakultas Kehutanan Universitas Negeri Papua, Manokwari.

Nurfazliza, K., Nizam, M.S., dan Supardi, M.N.N., 2012. Association of Liana Communities with Their Soil Properties in a Lowland Forest of Negeri Sembilan, Peninsular Malaysia. Sains Malaysiana, 41(6):679-690.

Padaki, A., dan Parthasarathy, N., 2000. Abundance and Distribution of Lianas in Tropical Lowland Evergreen Forest of Agumbe, Central Western Ghats, India. Tropical Ecology, 41(2):143-154.

Prechzsch, H., 2009. Forest Dynamics, Growth and Yield: From Measurement to Model. SpringerVerlag, Berlin. Pp 279-283.

Putz, F.E., dan Chai, P., 1987. Ecological Studies on Lianas in Lambir National Park, Sarawak, Malaysia. Journal of Ecology, 75(2):523-531.

Reddy M.S., dan Parthasarathy N., 2006. Liana Diversity and Distribution on Host Trees in Four Inland Tropical Dry Evergreen Forests of Peninsular India. Tropical Ecology, 47(1):109123.

Schnitzer, S.A, dan Bongers, F., 2011. Increasing Liana Abundance and Biomass in Tropical Forests: Emerging Patterns and Putative Mechanisms. Ecology Letters, 14(4):397-406.

Schnitzer, S.A., Dalling, J.W., dan Carson, W.P., 2000. The Impact of Lianas on Tree Regeneration in Tropical Forest Canopy Gaps: Evidence for An Alternative Pathway of GapPhase Regeneration. Journal of Ecology, 88(4):655-666.

Schnitzer, S.A., dan Bongers, F., 2002. The Ecology of Lianas and Their Role in Forests. Trends In Ecology \& Evolution, 17(5):223230.

Schnitzer, S.A., Van der Heijden, G., Mascaro, J., dan Carson, W.P., 2014. Lianas in Gaps 
Reduce Carbon Accumulation in a Tropical Forest. Ecology, 95(11):3008-3017.

Sirami, E.Y.I.V., Sadono, R., dan Marsono, D., 2014. Karakteristik Habitat Merbau [Intsia bijuga (Colebr.) O. Kuntze] di Taman Wisata Alam Gunung Meja Manokwari. Jurnal Beccariana, 15(1):39-44.

Tay, A.C., Abdulah, A.M., Awang, M., dan Furukawa, A., 2007. Midday Depression of
Photosynthesis in Enkleia malaccensis, A Woody Climber in A Tropical Rainforest. Photosynthetica, 45(2):189-193.

Van der Heijden, G.M.F., dan Phillips, O.L., 2009. Liana Infestation Impacts Tree Growth in A Lowland Tropical Moist Forest. Biogeosciences, 6(10):2217-2226. 